\title{
Los discursos institucionales sobre la pandemia COVID-19 dirigidos a la infancia en YouTube ${ }^{1}$
}

\author{
Alex Iván Arévalo Salinas²; Nicole Mazzucchelli Olmedo ${ }^{3}$; Astrid Arévalo Salinas ${ }^{4}$
}

\section{Introducción}

La crisis sanitaria por la pandemia del COVID-19 ha propiciado el desarrollo de una serie de campañas audiovisuales generadas por las administraciones públicas para informar sobre los efectos de esta crisis sanitaria y difundir las medidas de prevención. Con el fin de analizar de qué forma esta producción audiovisual se ha dirigido a la infancia, se propone como objetivo general estudiar los vídeos publicados por las administraciones públicas en el contexto de esta pandemia como mecanismo de comunicación en salud. Para tales efectos, se procede al estudio mediante el criterio predefinido (covid-niños/as) de los 3 vídeos con mayor número de visualizaciones, que permita analizar el tipo de comunicación audiovisual dirigido a la infancia y sus enfoques. Se revisan los indicadores de impacto, discurso y recepción. Los resultados dan cuenta de una escasa producción audiovisual dirigida a la infancia, una baja densidad de reproducciones, en relación a piezas producidas y/o publicadas por otros tipos de emisores. Esto plantea la necesidad de que las administraciones públicas indaguen en los discursos y estrategias que permiten tener repercusión en Youtube y dar cabida a estrategias que promuevan la información en la infancia.

\section{Contextualización}

La pandemia del COVID-19 ha provocado impactos sanitarios de distinta envergadura a lo largo de los países. Diariamente, los reportes oficiales son esperados por la ciudadanía para conocer la evolución de la pandemia. Al informar a la población sobre los riesgos, se puede minimizar la probabilidad de que las personas tomen decisiones inadecuadas, pudiendo además incrementar la confianza en las autoridades (Ancinas, 2007).

La capacidad de las administraciones públicas de sensibilizar sobre buenas conductas y comportamientos responsables ha sido categorizada en diversos trabajos como publicidad institucional (Cortés, 2008; García López, 2001). Cortés (2007: 228) destaca que con la publicidad institucional se puede "educar positivamente o lograr la aceptación de un código de conducta y/o valores orientados a la mejora de las relaciones sociales", desde los principios de la Cultura de Paz (Cortés, 2008).

En el contexto actual de la pandemia del COVID-19 cobra relevancia las campañas de comunicación y publicidad institucional que fomentan una actuación responsable de la ciudadanía en relación al cumplimiento de las recomendaciones sanitarias (distanciamiento social, protocolos sanitarios, restricciones para evitar la propagación del virus), como parte de una estrategia institucional de emergencia. Esto se enmarca en lo que se conoce como comunicación en salud definida como:

\footnotetext{
Este artículo es parte de los resultados del proyecto "La participación juvenil como herramienta de desarrollo social, económico, político y cultural en el espacio transfronterizo (España-Portugal)", con ref. IB16097, financiado por la Junta de Extremadura y por el Fondo Europeo de Desarrollo Regional - "Una manera de hacer Europa" y el proyecto "Converging Horizons: Production, Mediation, Reception and Effects of Representations of Marginality”, con ref. PIA-ANID/ANILLOS SOC180045. Financiado por la Agencia Nacional de Investigación y Desarrollo, ANID-Chile, específicamente por el Programa de Investigación Asociativa.

2 Universidad de Extremadura, España.

E-mail: aarevalo@uji.es

Pontificia Universidad Católica de Valparaíso, Chile y Universidad Autónoma de Barcelona, España.

E-mail: nicole.mazzucchelli@gmail.com

4 Universidad de Valparaíso, Chile.

E-mail: astrid.arevalo@uv.cl
}

Soc. Infanc. 4, 2020: 185-288 
El arte y las técnicas para informar, influir y motivar al público sobre temas de salud relevantes desde la perspectiva individual, comunitaria e institucional. Se ocupa de la prevención de enfermedades, las políticas de salud y el mejoramiento de la calidad de vida de las comunidades y los individuos (Busse y Godoy, 2016:10).

Uno de los espacios más relevantes para llevar a cabo este tipo de acciones comunicativas es Youtube, al ser el segundo sitio web más visualizado en el mundo, según los datos de Alexa Internet (2019). YouTube permite divulgar contenidos audiovisuales, pero también cumple la función de repositorio para posteriores utilidades. Además las personas tienen espacios de participación pudiendo compartir los materiales, hacer comentarios o calificar las producciones audiovisuales. A lo que se suma la posibilidad de que los vídeos sean remediados en otras redes sociales aumentando con ello el impacto inicial.

A partir de lo anterior, el presente trabajo tiene como objetivo analizar las producciones audiovisuales difundidas desde YouTube dirigidas a la infancia y que han sido generadas por instituciones públicas en el contexto de la pandemia COVID-19 como parte de estrategias de comunicación en salud.

\section{Método}

Para el abordaje del objetivo propuesto, se realiza una búsqueda en YouTube de la producción audiovisual generada por las administraciones públicas dirigida a la infancia, que contengan en su título y descripción el concepto clave de coronavirus-niños/as. De los resultados, se seleccionan los 3 vídeos con mayor número de visualizaciones.

La metodología empleada aplica algunos aspectos de la propuesta de investigación de YouTube de Arévalo Salinas (2018), que estudia este tema desde tres ámbitos: emisor, discurso y recepción. Cabe destacar, que se opta por la elección del término coronavirus por sobre covid, dada su mayor utilización en las búsquedas de Internet, tal como lo evidencian los datos de Google Trends.

En los 3 vídeos que componen el corpus de estudio se revisarán los siguientes aspectos:

- Análisis del número de visualizaciones para conocer el ranking en relación al total de vídeos

- Análisis de los aspectos técnicos (incorporación de voz en off o utilización de animaciones), su nivel creatividad en la forma de sensibilizar y el discurso incluido en estas producciones

- Descripción del apartado de presentación de los vídeos para analizar su relevancia como espacio complementario de información

- Revisión de los comentarios y su contenido para visualizar su impacto como espacios deliberativos

La recopilación de los datos se hizo el 19 de mayo de 2020. Señalamos la fecha considerando la rapidez de los cambios de información que acontecen en las redes sociales.

\section{Resultados}

El análisis según las palabras claves coronavirus y niños/as evidencian la escasez de vídeos generados por las instituciones públicas centrados en la infancia, que se expresa en la ubicación general de los 3 primeros en el ranking de los más visualizados: 112, 148 y 289. Además, los vídeos presentan un impacto reducido, en comparación a las piezas audiovisuales con mayores indicadores emitidos por diferentes tipos de emisores (medios informativos, canales de aprendizaje de niños y niñas, Youtubers, campañas informativas de la administración genéricas, entre otras). De los tres vídeos con mayor número de visualizaciones generados por las administraciones públicas, dos pertenecen al gobierno mexicano y sus respectivas unidades administrativas.

Tabla. 1. Análisis de datos generales de los 3 vídeos más visualizados sobre coronavirus y niños/as

\begin{tabular}{|l|l|l|l|l|}
\hline \multicolumn{1}{|c|}{ Nombre del vídeo } & \multicolumn{1}{|c|}{ Emisor } & \multicolumn{1}{|c|}{$\begin{array}{c}\text { Número de } \\
\text { visualizaciones }\end{array}$} & $\begin{array}{l}\text { Cantidad de co- } \\
\text { mentarios }\end{array}$ & \multicolumn{1}{c|}{ Ranking } \\
\hline $\begin{array}{l}\text { Coronavirus. Así me lavo las } \\
\text { manos }^{5}\end{array}$ & $\begin{array}{l}\text { Ministerio de Sanidad de } \\
\text { España }\end{array}$ & $\begin{array}{l}\text { No habilitada la } \\
\text { opción }\end{array}$ & 112 \\
\hline Ciérrale la puerta al Covid-19 $^{6}$ & Secretaria de Salud de México & 53.054 & 67 & 148 \\
\hline $\begin{array}{l}\text { Escuchar a las niñas y los ni- } \\
\text { ños en tiempos de coronavirus }\end{array}$ & $\begin{array}{l}\text { Instituto Nacional Electoral de } \\
\text { México }\end{array}$ & $\begin{array}{l}\text { No habilitada la } \\
\text { opción }\end{array}$ & 289 \\
\hline
\end{tabular}

Disponible en: https:/www.youtube.com/watch? $\mathrm{v}=\mathrm{jPqlHzfrl} 8 \mathrm{k} \& \mathrm{t}=1 \mathrm{~s}$

Disponible en: https://www.youtube.com/watch?v=fpL6GXwNoI8

Disponible en: https:/www.youtube.com/watch?v=Iss-NKA6X9g 
El vídeo con mayor número de visualizaciones corresponde al Ministerio de Sanidad de España con el título Coronavirus. Así me lavo las manos, que alcanzó 114.025 visualizaciones. Se trata de un vídeo educativo que enseña a los niños y niñas a realizar una limpieza adecuada de las manos. En esta producción audiovisual aparece un niño -sin visualizar su cara- que demuestra el procedimiento correcto. La voz en off (protagonizada por un niño) explica cada fase de la limpieza de las manos, siendo resaltada cada etapa con un título. No aparecen distractores en el mensaje, sino por el contrario la atención se ubica en el correcto ejercicio del lavado de manos.

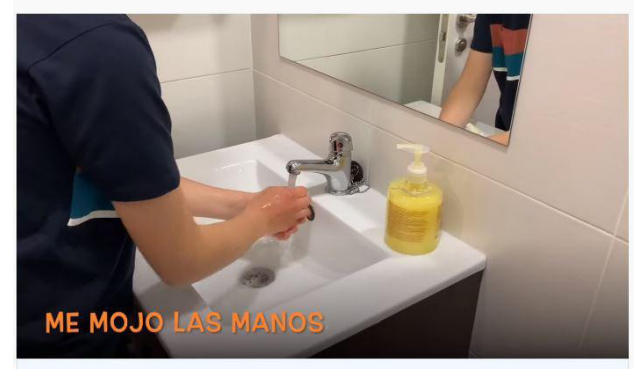

Imagen 1. Vídeo Coronavirus. Así me lavo las manos.

Fuente: Canal de YouTube del Ministerio de Sanidad de España.

El segundo vídeo con más visualizaciones es una canción del género musical denominado "cumbia”, cuya autoría corresponde a la Secretaría de Salud de México. Si bien en este vídeo no se menciona en su título a los niños/as, tienen un lugar central al ser incorporados en las animaciones en 19 de los 30 segundos de duración de esta pieza audiovisual. Este vídeo registró 53.054 visualizaciones y aporta pautas de actuación en relación al lavado de las manos; informa sobre las restricciones al contacto físico e invita a mantener el distanciamiento social. Esto último con la rima: "Déjame que te salude de ojitos, bien lejitos". También es un llamado a mantener la calma y a no convertirse en promotor de la desinformación con la frase: "Quítate la paranoia y no difundas informaciones falsas".

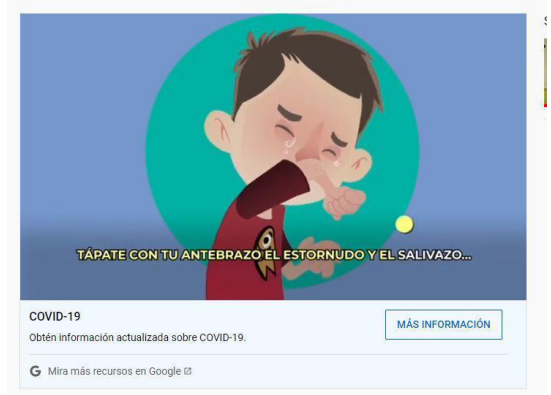

Imagen 2. Vídeo Ciérrale la puerta al Covid-19.

Fuente: Canal de YouTube de la Secretaría de Salud de México.

El tercer vídeo más visualizado pertenece al Instituto Nacional Electoral de México, siendo el más extenso, con 4 minutos y 57 segundos. En esta pieza audiovisual se incorporan las recomendaciones del periodista José Gordon dirigido a los padres sobre cómo informar a los niños y niñas sobre el contexto de emergencia que están viviendo. También se informa sobre pautas de higiene para evitar la propagación del virus incorporando animaciones y una canción que refuerza este mensaje. Destaca por ser una propuesta que fomenta el diálogo, al sensibilizar a los padres de que los niños tienen voz y que deben ser escuchados. La voz en off señala que "lo primero que debemos hacer es escucharlos y estar abiertos a sus preguntas". Otro fragmento señala: "Si tenemos miedo hay que hablar, así es como se enfrentan la crisis en la vida... lo que necesitamos es conocimiento y empatía. Saber escucharnos".

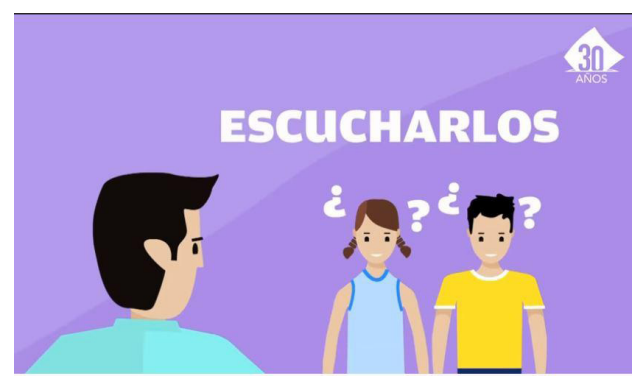

Imagen 3. Vídeo Escuchar a las niñas y los niños en tiempos de coronavirus. Fuente: Canal de YouTube del Instituto Nacional Electoral de México. 
El análisis realizado nos evidencia que las producciones de las administraciones públicas de México presentan una mayor profundización y creatividad. Por ejemplo, el vídeo Ciérrale la puerta al Covid-19 incorpora una canción para difundir las recomendaciones sanitarias incluyendo animaciones. Esta canción de cumbia toma en consideración aspectos culturales, como la influencia de las melodías bailables en México y en gran parte de la región latinoamericana.

Los tres vídeos presentan una información reducida en el espacio de descripción de YouTube, lo cual dificulta que los ciudadanos tengan una contextualización detallada del tema o puedan acceder a ella a través de páginas web enlazadas. El vídeo de la Secretaria de Salud de México no aporta información específica y se remite a presentar el enlace web. Por su parte, el vídeo del Instituto Nacional Electoral de México añade el objetivo, pero no incorpora una web. Situación similar acontece en el caso de la producción audiovisual del Ministerio de Sanidad de España que incorpora la siguiente frase: "La higiene es fundamental para evitar cualquier infección. Este video enseña a los más pequeños de las casas a lavarse bien las manos".

En cuanto a los niveles de participación en los espacios de comentarios, solo el vídeo emitido por la Secretaría de Salud de México registra este tipo de actividad, con 67 opiniones. Sin embargo, se trata de comentarios breves, de los cuales 11 de ellos expresan una satisfacción por el contenido y por su utilidad como aprendizaje. Por su parte, 2 comentarios destacan el aporte de este vídeo para la sensibilización de los niños/niñas. Sin embargo, no es posible rastrear si estos comentarios son propuestos desde el público objetivo (niños y niñas). A pesar de la necesidad de fomentar la conexión entre la ciudadanía y las administraciones públicas, los vídeos del Ministerio de Sanidad de España y del Instituto Nacional Electoral de México no tienen habilitada la opción para realizar comentarios.

El impacto de los vídeos analizados es reducido, si lo comparamos con los datos de las 3 producciones audiovisuales con mayor número de visualizaciones, sin establecer filtros según el tipo de emisor, que fluctúan entre los 4 y 9 millones de visualizaciones. Los vídeos más vistos en YouTube que contienen las palabras claves coronavirus y niños/as son los siguientes:

- Lávate las manos para protegerte del coronavirus del canal Marie Leiner registró 8.816 .983 visualizaciones.

- Coronavirus What is Coronavirus? del canal Peekaboo Kidz con 4.177.024 visualizaciones, en idiomas inglés.

- ¿Qué es el coronavirus? Explicación para niños, con 4.148.375, emitido por el canal Happy Learning Español.

Todos estos vídeos insertan dibujos animados para lograr captar la atención de los niños y niñas enfocándose en una infancia más temprana.

\section{Conclusiones}

Los resultados nos expresan que las administraciones públicas no están promoviendo con intensidad campañas centradas en la población infantil, y las que se han realizado no logran niveles elevados de impacto según los indicadores medidos en este artículo. Es necesario, por tanto, que se promuevan campañas dirigidas a grupos específicos como niños, niñas y adultos mayores, que pudieran requerir un tratamiento, especificidad y/o contenido particular, para su comprensión de la crisis sanitaria e integración como sujetos activos de la información de la cual se les hace parte.

Las administraciones públicas deben analizar los discursos e información que tienen repercusión y viralidad, para adaptar estos elementos a su propia comunicación y publicidad institucional. En este sentido, se requieren de estudios que hagan seguimiento de estos vídeos, en diferentes espacios, especialmente en cómo se propagan por otras redes sociales y qué contenidos incentivan un espacio deliberativo. Por lo tanto, es necesario definir una estrategia, que conecte con la ciudadanía, utilizando diferentes espacios y canales, que sea capaz de llegar también a diferentes grupos.

En esta línea, es deseable que la información difundida a la infancia, a través de los canales oficiales, sea capaz de transitar de considerar a los niños como receptores pasivos de la información a ubicarlos como sujetos activos y protagonistas de una particular construcción de mundo, conforme a lo propuesto desde los nuevos estudios de la infancia (Vergara, Peña, Chávez y Vergara, 2015).

Las campañas analizadas están desaprovechando los espacios que brinda YouTube. En primer lugar, la información complementaria es escasa, que permitiría al ciudadano conocer más detalles. En segundo lugar, aunque se trata de países democráticos como México y España, no se fomenta una comunicación bidireccional en YouTube, al no estar habilitado los espacios de participación vía comentarios.

\section{Referencias bibliográficas}

Ancinas, M. P. (2007). Información a la población en situaciones de emergencia y riesgo colectivo. Psychosocial Intervention, 16(3), 303-321 (en línea). http://scielo.isciii.es/scielo.php?script=sci_arttext\&pid=S1132-05592007000300002\&lng=es\&tl$\mathrm{ng}=\mathrm{es}$. 
Arévalo Salinas, Á. I. (2018). Propuesta metodológica para el análisis de YouTube y su relación con los movimientos sociales. En II Congreso Internacional Move.net sobre Movimientos Sociales y TIC (2018), p 25-34. Grupo Interdisciplinario de Estudios en Comunicación, Política y Cambio Social de la Universidad de Sevilla (COMPOLÍTICAS).

Alexa Internet Inc (2019). The top 500 sites on the web (en línea). http://www.alexa.com/topsites

Busse, P., Godoy, S. (2016). Comunicación y salud. Cuadernos.info, (38), 10-13 (en línea). https://scielo.conicyt.cl/scielo.php?script=sci_arttext\&pid=S0719-367X2016000100001\&lng=es\&tlng=n, acceso 20 de mayo de 2020.

Cortés, A. (2007). Cultura de Paz y Publicidad institucional. El Estado en el fomento de la cultura a través de la publicidad televisiva. Jaén: Alcalá editorial.

Cortés, A. (2008). Publicidad televisiva del Estado y el fomento de la cultura de paz, Revista Latina de Comunicación Social, 63, 98-105 (en línea). http://www.ull.es/publicaciones/latina/_2008/11_Malaga/Alfonso_Cortes.html.

García López, M. (2001). Publicidad institucional: El Estado anunciante. Málaga: Universidad de Málaga.

Vergara, A., Peña, M., Chávez, P., Vergara, E. (2015). Los niños como sujetos sociales: El aporte de los Nuevos Estudios Sociales de la infancia y el Análisis Crítico del Discurso. Psicoperspectivas, 14(1), 55-65. doi: 10.5027/psicoperspectivas-Vol14-Issue1-fulltext-544 